\title{
Nova abordagem para o estudo das viagens geradas nas instituições de ensino
}

\author{
Maria Alice Prudêncio Jacques ${ }^{1}$; Ângela Bertazzo²; \\ Jorge Galarraga ${ }^{3}$; Marcelo Herz ${ }^{4}$
}

\begin{abstract}
Resumo: A previsão do número de viagens geradas pelos polos geradores de viagens (PGVs) é indispensável para estudos de avaliação do impacto da implantação destes empreendimentos. No caso das instituições de ensino (IE), as características especiais das viagens e de atendimento dos alunos dos diferentes níveis, recomendam a realização dos estudos de avaliação de impacto que possam reconhecer o efeito da adoção de políticas de transporte sustentáveis. Com base na revisão de estudos de geração de viagens para IE descritos na literatura, este trabalho apresenta uma nova abordagem para o estudo das viagens geradas nas IE, que inclui proposta para classificação das viagens geradas pelas IEs e para procedimentos voltados à determinação das taxas e modelos e à realização de estudos de impacto das IEs. A proposta formulada permite que os estudos de impacto considerem cenários alternativos referentes à adoção de medidas de gerenciamento da demanda.
\end{abstract}

\begin{abstract}
The estimation of the number of trips that may be generated by a specific land use is essential to study and evaluate the impact of new generators. In the case of Educational Institutions (EI), the special characteristics of travel pattern for students of different levels supports the needs to develop studies that can recognize the effects of adopting sustainable transport policies. Based on specific literature review, this paper presents a new approach to study the trips generated by an EI. It includes a proposal for classification of generated trips to estimate rates and models, and also a procedure to consider the impact derived from the implementation of demand management measures.
\end{abstract}

\section{INTRODUÇÃO}

Os empreendimentos classificados como polos geradores de viagens (PGVs), embora de diferentes naturezas, têm em comum o potencial de atrair e produzir um número de viagens que impactam os sistemas viários e de transportes da região onde se localizam. Dependendo das condições desses sistemas e do número de viagens geradas, a implantação desses empreendimentos pode trazer consequências bastante negativas para a qualidade de vida da população. Entretanto, os polos gerados de viagens também têm o potencial de gerar benefícios econômicos para a mesma região, sobretudo em termos da oferta de novos postos de trabalho, da geração de impostos e da prestação de serviços desejados pela comunidade, dentre outros aspectos.

Esta condição impõe a necessidade de que a implantação dos PGVs, independentemente de sua natureza, seja precedida de estudos específicos voltados à avaliação dos impactos que produzem. Somente a partir desta avaliação é que o gestor municipal poderá deci-

\footnotetext{
${ }^{1}$ Maria Alice Prudêncio Jacques, Universidade de Brasília, Brasília, DF, Brasil. (e-mail: mapj@unb.br).

${ }^{2}$ Ângela Bertazzo, Centro Universitário Izabela Hendrix, Belo Horizonte, MG, Brasil. (e-mail: angela.bertazzo@hotmail.com).

${ }^{3}$ Jorge Galarraga, Universidad de Córdoba, Córdoba, Argentina. (e-mail: jorgala@efn.uncor.edu).

${ }^{4}$ Marcelo Herz, Universidad de Córdoba, Córdoba, Argentina. (e-mail: mherz@arnet.com.ar).
}

Manuscrito recebido em 13/1/2010 e aprovado para publicação em 5/3/2010. Este artigo é parte de TRANSPORTES, volume XVIII, número 1, março de 2010. ISSN: 2237-1346 (online). dir pela implantação ou não do empreendimento no local pretendido e, no caso dessa implantação ser autorizada, quais as medidas que o empreendedor deve tomar no sentido de reduzir ao máximo possível os impactos negativos dela decorrentes. A realização de estudos de impactos de PGVs é, via de regra, uma exigência legal.

Em linhas gerais, o processo de análise dos PGVs é comum aos diferentes tipos, e tem uma estrutura já bastante difundida na literatura técnica especializada brasileira e de outros países. Um dos elementos mais importantes desses estudos é a estimativa do número de viagens produzidas e atraídas pelos empreendimentos: as viagens geradas. Para esta estimativa, estão disponíveis na literatura diferentes modelos, que refletem as condições específicas dos empreendimentos integrantes da amostra considerada no estudo. Estes modelos referem-se à estimativa total das novas viagens geradas pelo PGV, levando em conta o modo de transporte utilizado.

As instituições de ensino (IE), nos seus diferentes níveis, são PGVs com algumas características específicas que requerem cuidados especiais na análise do impacto que produzem sobre a circulação do tráfego nas vias próximas ao empreendimento. Os picos de geração de viagens desses polos são, em geral, coincidentes com os picos de tráfego no sistema viário. Outro aspecto relevante é que as viagens geradas pelas instituições de ensino, similarmente ao que ocorre com as viagens realizadas com o propósito de trabalho, ocorrem de modo regular e previamente programado, especialmente nos dias úteis. Dependendo do 
nível do ensino e da distribuição modal das viagens, estas instituições exibem necessidades distintas em termos de vagas de estacionamento e de locais para operações de embarque e desembarque de passageiros nas suas imediações.

A relevância do estudo das viagens geradas nas instituições de ensino prende-se, dentre outros aspectos, à necessidade constante da ampliação do número desses empreendimentos e ao fato de que, dado o tipo de serviço que oferecem, eles tendem a ser implantados em áreas densamente ocupadas.

Os estudos de geração de viagens disponíveis na literatura para as instituições de ensino foram elaborados a partir de premissas básicas utilizadas nos modelos desenvolvidos para outros tipos de PGVs, sobretudo com relação à classificação das viagens e ao uso dos valores produzidos pelos modelos de previsão. Essas premissas, no entanto, dificultam o uso dos resultados do estudo para efeito da adoção de estratégias voltadas à redução do impacto desses empreendimentos.

Neste contexto, o presente artigo visa apresentar um novo enfoque para a realização do estudo de viagens geradas nas instituições de ensino, que permita um melhor entendimento das características dessas viagens e que facilite o uso das estimativas como instrumento de gerenciamento da nova demanda.

O trabalho está organizado em cinco seções. Seguindo esta seção de introdução, é apresentada e analisada a metodologia usualmente adotada para o estudo da geração de viagens em instituições de ensino. Na Seção 3 é apresentada uma revisão bibliográfica sobre os estudos de geração de viagens em instituições de ensino, onde são identificados e analisados os principais elementos desses estudos. Como base nas análises realizadas nas Seções 2 e 3 , é apresentada na quarta seção uma proposta de nova abordagem para a realização deste tipo de estudo. A última seção contém as principais conclusões do trabalho e as recomendações para sua continuidade.

\section{METODOLOGIAS PARA A REALIZAÇÃO DE ESTUDOS DE GERAÇÃO DE VIAGENS}

Nesta seção são apresentadas as duas metodologias para a realização de estudos de geração de viagens que subsidiram a elaboração da nova abordagem apresentada na Seção 4, especificamente voltada para o estudo da geração de viagens em instituições de ensino (IE). São elas: metodologia do ITE e metodologia de Bryans e Nielsen.

\subsection{Metodologia do ITE}

Dentre as metodologias disponíveis na literatura para a estimativa das viagens geradas por PGV, a desenvolvida pelo Institute of Transportation Engineering
(ITE, 2001) é uma das referências mais adotadas no Brasil e nos demais países ibero-americanos. De acordo com essa metodologia, viagens geradas em um determinado período de tempo são as viagens atraídas e produzidas pelos PGVs durante este período. Neste contexto, viagens atraídas são aquelas que se destinam ao PGV e as viagens produzidas são as que se originam no PGV.

\subsubsection{Etapas metodológicas}

As principais etapas dessa metodologia, referentes à determinação e utilização das taxas e modelos de geração podem ser resumidas como segue:

a) definição do número de instituições a serem incluídas na amostra: para efeito da determinação de novas taxas o ITE recomenda estudar pelo menos 3 locais, e para novos modelos, pelo menos 05 locais;

b) seleção das instituições a serem analisadas para efeito da determinação das taxas e modelos de geração de viagens: as instituições devem ser escolhidas de modo a assegurar que a amostra represente efetivamente a população alvo da pesquisa; nessa seleção, devem ser consideradas não só as características da instituição em si, como também as condições do uso e ocupação do solo nas suas imediações, juntamente com as características do sistema de transporte público e do tráfego nas vias adjacentes;

c) definição das variáveis a serem estudadas em cada instituição da amostra: essas variáveis devem ser selecionadas em função do seu potencial em explicar a priori a realização das viagens. Seus valores devem ser de fácil obtenção nas instituições da amostra, e de fácil previsão para as futuras utilizações das taxas e modelos;

d) período da pesquisa: deve compreender os dias da semana e horários relacionados às características das viagens de rotina para o empreendimento, de modo a permitir a identificação dos períodos de pico;

e) coleta dos dados: dentre as diversas formas que podem ser adotadas para a coleta dos dados estão: entrevistas com aos responsáveis pela operação do PGV, contagens automáticas ou manuais das entradas e saídas de veículos do empreendimento e aplicação de questionários aos usuários. Esta última forma tem sido aplicada em estudos para IE, permitindo tanto a determinação do número de viagens quanto a identificação da distribuição modal e da taxa de ocupação dos automóveis;

f) análise dos dados: estudos de correlação entre o número de viagens realizadas e as variáveis selecionadas devem ser realizados de modo a 
permitir a identificação da(s) variável(eis) explicativas dessas viagens. A partir da identificação dessas variáveis podem então ser calculadas taxas de geração de viagens de automóveis e/ou de pessoas e de veículos. Essas taxas representam o número médio de viagens geradas por unidade de uma variável explicativa específica. Nos casos em que o tamanho da amostra permitir, devem ser usadas técnicas de análise de regressão para a obtenção de equações para a estimativa do número de viagens geradas. O ITE apresenta equações somente quando: $\mathrm{R}^{2}$ é maior ou igual a 0,5; o tamanho da amostra é superior a 4; e o número de viagens cresce com o aumento do valor da variável independente (ITE, 2008). Os dados coletados também são empregados para a realização de análises referentes ao padrão das viagens realizadas (dia da semana e período do dia em que ocorre o maior número de viagens; distribuição das viagens por categoria de usuário; distribuição modal; dentre outros aspectos);

g) utilização das taxas e modelos: é recomendável que as taxas e modelos só sejam aplicados para estudar empreendimentos cujo porte se encontre entre o limite mínimo e o limite máximo do porte dos PGVs integrantes da amostra utilizada. Neste caso, a avaliação do porte deve ser feita com base nos valores da(s) variável(eis) explicativa(s) do modelo. Para novos empreendimentos nessa condição, o número de viagens geradas é então estimado mediante a aplicação das taxas e/ou modelos de geração específicos, utilizando-se os valores correspondentes das variáveis explicativas consideradas.

\subsubsection{Análise}

Para efeito da elaboração das taxas e modelos de geração de viagens, o ITE recomenda que as viagens sejam classificadas em três categorias: viagens primárias (geralmente de base domiciliar), viagens desviadas e viagens não-desviadas. As taxas e modelos de geração de viagens consideram somente as viagens primárias e as viagens desviadas. Conforme observado por Ewing et al. (2004), as viagens por motivo ensino são compulsórias. Isto indica que, mesmo que as viagens por motivo ensino não tenham base domiciliar, critério importante na classificação tradicional de viagens para indicar que o empreendimento de fato produziu a nova viagem, elas podem ser dominantes no plano de viagens diárias de cada indivíduo. Isto é, mesmo no caso de não ter base domiciliar, a ida à escola ocorre regularmente e é função da presença do empreendimento. Neste contexto, para o estudo de instituições de ensino superior, Souza (2007) sugere a substituição do termo viagem primária por viagem específica. No entanto, para alguns tipos de instituições de ensino, onde os estudantes não têm idade para conduzir veículos, é conveniente desagregar as viagens específicas em função do comportamento do condutor: se é usuário da instituição e precisará estacionar o seu veículo, ou se dá carona a um usuário da instituição. Neste último caso, a realização da viagem exigirá um local adequado para as operações de embarque e desembarque e não mais uma vaga para estacionamento de longa duração. Na Seção 4 deste artigo é apresentado um refinamento da atual forma de classificar as viagens geradas nas instituições de ensino.

Embora as taxas e modelos elaboradas pelo ITE para as instituições de ensino limitem-se às viagens realizadas por automóvel (em termos de viagens veiculares), em vários estudos já se verifica a aplicação dos resultados da análise do padrão de viagens para a e elaboração de taxas e modelos de geração desagregados por modo de transporte. Isto é, um dos aspectos negativos da metodologia original do ITE (2001), que é o seu foco nas viagens veiculares, já se encontra superado em diferentes trabalhos onde esta metodologia foi empregada como referência.

Aspectos tais como a determinação de taxas e modelos a partir de amostras muito pequenas, com a possibilidade de falta de significância estatística e decorrente fragilidade na representatividade efetiva da população alvo, também têm merecido observações em vários estudos. Nestes, os autores em geral chamam a atenção para o problema e instam os futuros usuários das taxas e modelos a considerar os valores estimados com algumas restrições, e a usar elementos complementares para efeito da previsão do impacto do PGV. Embora também fazendo considerações neste sentido, e criticando duramente a forma pela qual as taxas e modelos divulgados pelo ITE são utilizados nos Estados Unidos, a análise da metodologia do ITE realizada por Shoup (2001) merece destaque especial com relação a outro aspecto.

O autor faz importantes considerações sobre as consequências da aplicação das taxas e modelos divulgados pelo ITE para a estimativa das viagens geradas por diferentes tipos de PGVs, mesmo quando essas taxas e modelos refletem devidamente a população alvo. Shoup (2001) aponta que, ao prever o número de viagens veiculares (e também o número de vagas de estacionamento) com base nestas ferramentas, admite-se que o novo empreendimento tenha padrão de viagens muito próximo do verificado nos PGVs incluídos na amostra. Isto é, quando o órgão que analisa o empreendimento usa as estimativas das viagens geradas para exigir do empreendedor padrões de projeto (inclusive de oferta de vagas de estacionamento) compatíveis com essa demanda, estará mantendo o status quo e, 
em geral, estimulando à realização de mais viagens motorizadas.

Ou seja, a forma da aplicação das taxas e modelos do ITE, ou de taxas e modelos resultantes dos estudos que seguem metodologia semelhante, precisa ser revista para que possa servir como instrumento efetivo de gerenciamento da mobilidade, visando contribuir para um transporte menos dependente do automóvel. Para tanto, a própria forma de tratar os dados coletados junto aos empreendimentos da amostra para a determinação dessas taxas e modelos precisa sofrer alguns ajustes.

\subsection{Metodologia de Bryans e Nielsen}

Esta metodologia foi elaborada para avaliação de projetos de empreendimentos residenciais. Baseia-se na indicação, dada pelo White Paper sobre o Futuro do Transporte, de que o conceito de "prever e prover" está sendo alterado no Reino Unido. A ênfase em planejar sistemas de transportes para atender a demanda de viagens geradas por novos empreendimentos está sendo modificada no sentido de privilegiar o planejamento de novos empreendimentos que reduzam a dependência do uso do automóvel (Bryans e Nielsen, 1999).

Neste contexto, os autores propõem uma metodologia de análise de novos empreendimentos, cujas principais etapas são:

Etapa 1: definir uma taxa de demanda de viagens com base nas características do empreendimento e da área onde o mesmo se localizará. Esta taxa é fruto da análise dos dados de viagens de empreendimentos com características gerais semelhantes às apresentadas pelo empreendimento em estudo;

Etapa 2: estabelecer uma taxa de geração de viagens sustentável, levando em conta as metas desejadas para a distribuição modal das viagens do novo empreendimento. Esta taxa pode ser determinada pelo levantamento de dados em empreendimentos semelhantes planejados de modo sustentável e pelo uso de modelos multimodais detalhados de uso do solo/transoporte, dentre outros métodos;

Etapa 3: avaliar o planejamento e projeto do empre- endimento de modo a verificar se a taxa de geração de viagens sustentável pode ser efetivamente atingida.

A Figura 1 apresenta a estrutura geral da metodologia.

Os autores reconhecem explicitamente que a determinação de taxas de geração de viagens sustentáveis, por si só, não reduz o número de viagens geradas por automóvel pelas novas residências. Eles destacam que a estratégia global para que isso ocorra inclui, também, o planejamento e projeto de serviços, facilidades e infraestruturas compatíveis com as metas estabelecidas.

\section{TAXAS E MODELOS DE GERAÇÃO DE VIAGENS PARA IE}

Nesta seção é apresentada uma breve revisão dos aspectos conceituais de estudos que tratam da definição de taxas e modelos para estimativa do número de viagens geradas por instituições de ensino. Na última seção é feita uma análise global dos estudos revisados.

\subsection{ITE (2008)}

Deste a primeira publicação do “Trip Generation” em 1976, o Instituto de Engenharia de Transportes (ITE) apresenta taxas e modelos de geração de viagens para instituições de ensino localizadas nos Estados Unidos. Na sua oitava edição (ITE, 2008) inclui usos do solo associados a diferentes níveis de ensino, com taxas e modelos definidos com base em um número variável de estudos. Tendo em vista o propósito de estimar o impacto das viagens geradas no trânsito e as necessidades de estacionamento, são publicadas somente taxas e modelos referentes a viagens veiculares, em diferentes períodos. As taxas e modelos elaborados para todos os níveis de instituição de ensino consideram uma das seguintes variáveis explicativas: número de alunos, número de empregados (docentes e pessoal administrativo) e superfície coberta. Na análise dos dados referentes às taxas de geração, verifica-se que os valores do desvio-padrão associado às taxas mostram graus de dispersão distintos.

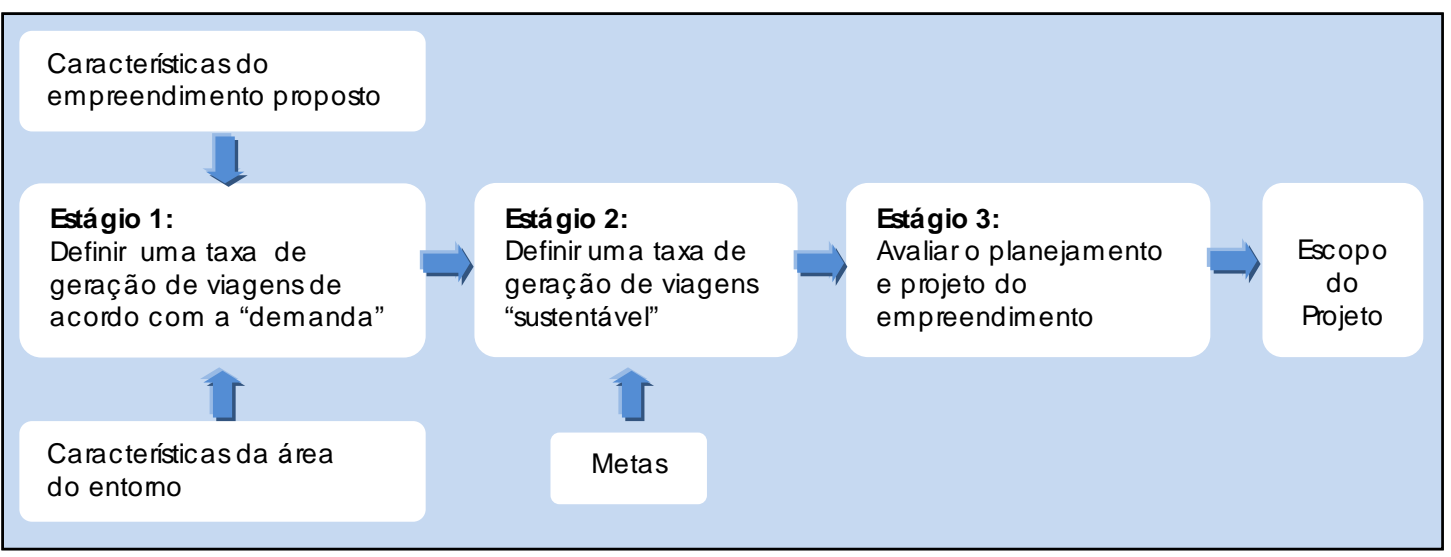

Figura 1. Estrutura da metodologia (Fonte: Bryans e Nielsen, 1999) 


\subsection{CET $(1983,2000)$}

A Companhia de Engenharia de Tráfego de São Paulo (CET) é pioneira no estudo de geração de viagens no Brasil. Em 1983, com base em uma amostra de 5 (cinco) escolas e faculdades da cidade de São Paulo, foram elaborados modelos para estimar o número médio de viagens atraídas pelas instituições na hora de pico. As variáveis explicativas consideradas foram: número de alunos; número total de salas de aula; e área total de salas de aula. Multiplicando-se as viagens atraídas por coeficientes específicos são determinadas as necessidades de vagas de estacionamento. No estudo realizado em 2000 são apresentadas taxas de distribuição modal para as viagens atraídas no início e produzidas no final dos turnos de instituições de ensino fundamental e médio. $\mathrm{O}$ estudo foi realizado a partir de uma amostra de 20 (vinte) escolas da cidade de São Paulo. Leva em conta o nível de ensino da escola, o turno, e a taxa média de ocupação do automóvel. Considera os modos de transporte por automóvel, a pé, por transporte escolar e por transporte coletivo regular. O número de vagas de estacionamento é estimado em função da quantidade de viagens atraídas por professores e funcionários.

\subsection{Pitsiava-Latinopoulu (2001)}

Estudos realizados na área metropolitana de Tselónica (Grécia) visaram observar a distribuição modal das viagens realizadas em instituições de ensino de diferentes níveis, a partir de questionários aplicados a estudantes e empregados (professores e funcionários) dessas instituições. Os resultados mostram a alta participação das viagens com o propósito estudo realizadas por modos diferentes do automóvel, que é uma informação relevante para países de renda média. Este tipo de distribuição modal não é contemplado pelas taxas e modelos do ITE. O modelo para a estimativa do número total de viagens diárias para as instituições universitárias foi obtido com uma amostra de 9 Faculdades, incluindo 615 alunos e cerca de 300 funcionários. A variável explicativa do modelo é a soma do número de alunos com o número de funcionários.

\subsection{Tectran $(2003,2004)$}

Apresenta taxas de geração de viagens diárias, com a utilização de fatores de hora de pico para estimar viagens atraídas na entrada e viagens produzidas na saída de instituições de ensino superior localizadas em Belo Horizonte. A variável explicativa para estimar as viagens diárias é o número total de usuários da instituição. Também apresenta modelos para estimar viagens horárias (atraídas ou produzidas) em função do número de alunos e fatores de hora de pico. Em todos os casos, as viagens geradas são transformadas em viagens por modo de transporte, levando em conta por- centagens de participação modal do automóvel, ônibus, a pé e outros modos observadas em instituições congêneres.

\subsection{Erwing et al. (2004)}

Este estudo é o primeiro nos Estados Unidos que examina, nas viagens realizadas para escolas primárias e secundárias, a relação entre a distribuição modal e um completo grupo de fatores. Baseado em dados de 15980 viagens da área metropolitana de Gainsville, Flórida, foram identificadas 709 viagens escolares, realizadas por diferentes modos: automóvel (77,3\%), transporte escolar $(14,8 \%)$, a pé $(4,5 \%)$ e de bicicleta $(3,4 \%)$. Outras 110 viagens escolares da amostra foram descartadas por não apresentarem dados completos. Foi elaborado um modelo logit multinomial tendo o automóvel como modo base e possuindo as seguintes variáveis explicativas: renda anual da familia, propriedade de automóvel per capta da família, posse de carteira de motorista (variável dummy), tempo de viagem a pé, tempo de viagem de bicicleta, cobertura média de calçadas nas zonas de origem e destino, e índice médio de acessibilidade para as zonas de origem e destino. Com base nos coeficientes obtidos para as variáveis do modelo, foi possível analisar, para a situação socioeconômica da área de estudo, a sensibilidade dos diferentes modos para ganhar ou perder viagens para instituições de ensino frente a mudanças nos valores das variáveis independentes.

\subsection{Souza (2007)}

Tem como objetivos determinar taxas e modelos de geração de viagens por automóvel, por ônibus e a pé. Foi realizado com base em uma amostra de 9(nove) instituições de ensino superior do Distrito Federal, Brasil. Os modelos apresentados possuem como variável dependente o número de viagens realizadas por alunos ou o número de viagens realizadas por todos os usuários da instituição no início e final de cada turno. Em todos os casos a variável independente é o número de alunos. Informa sobre a distribuição modal, e classifica as viagens por automóvel em específicas, desviadas e de passagem; as taxas e modelos calculados no estudo se referem à soma das viagens específicas e desviadas.

\subsection{Bertazzo (2008)}

Determina taxas e modelos de geração de viagens para instituições de ensino médio, e foi realizado a partir de uma amostra formada por 5(cinco) instituições públicas e por outras 5(cinco) instituições privadas localizadas no Distrito Federal, Brasil. Além de fazer a distinção por tipo de instituição (pública ou privada), tem em conta se as viagens são atraídas (início do turno) ou produzidas (final do turno), se são realizadas por alunos ou funcionários e, ainda, se são realizadas nos 
períodos de pico da manhã, tarde ou noite. Considera os modos de transporte por automóvel, por ônibus e a pé.

\subsection{Herz et al $(2007,2009)$}

O trabalho descreve viagens diárias de pessoas, de veículos e a distribuição modal para 13 (treze) instituições de ensino superior da cidade de Córdoba, Argentina. São apresentados modelos de geração de viagens diárias de pessoas para viagens motorizadas individuais (automóvel, táxi e moto), viagens motorizadas em transporte coletivo (regular e contratado), viagens não motorizadas (a pé e de bicicleta) e viagens totais. Também apresenta um modelo de viagens diárias veiculares por automóvel. Em todos os casos, a variável independente é o número de alunos. Foi incluída uma variável dummy para representar a distância da instituição de ensino ao centro da cidade.

\subsection{Análise}

Os estudos revisados apresentaram aspectos metodológicos diferenciados, decorrentes, sobretudo, do seu propósito em termos do tipo de instituição e do elemento a ser estimado com as taxas e modelos. Alguns desses aspectos estão resumidos na Tabela 1.

A abordagem original do ITE, com modelos e taxas para estimar o número de viagens veiculares, se mantém na maioria dos estudos revisados. Entretanto, é possível observar a crescente orientação para estimativas do número de viagens de pessoas e sua distribuição modal, que é bastante variável em função das condições socioeconômicas dos usuários e da área de localização dos PGVs. A Tabela 2 mostra uma síntese dos modos de transporte considerados nos estudos revisados.

A distribuição modal é extremamente relevante para instituições de ensino, pois as viagens para esse tipo

Tabela 1. Análise comparativa da dimensão metodológica de cada estudo

\begin{tabular}{|c|c|c|c|c|c|}
\hline Estudo & Tipo de Instituição & $\begin{array}{r}\text { Tamanho } \\
\text { amostra } \\
\end{array}$ & $\begin{array}{l}\text { Objetivo da } \\
\text { estimativa }\end{array}$ & $\begin{array}{c}\text { Variáveis } \\
\text { explicativas }\end{array}$ & $\begin{array}{c}\text { Obtenção dos } \\
\text { dados }\end{array}$ \\
\hline ITE (2008) & $\begin{array}{l}\text { Infantil, } \\
\text { Fundamental, } \\
\text { Médio, } \\
\text { Superior } \\
\end{array}$ & $\begin{array}{c}48 \\
25 \\
68 \\
6 \\
\end{array}$ & $\begin{array}{l}\text { Viagens geradas em } \\
\text { veiculo na hora pico } \\
\text { e por dia }\end{array}$ & $\begin{array}{c}\text { № de alunos, } \\
\text { № de funcionários, } \\
\text { Área bruta total }\end{array}$ & $\begin{array}{l}\text { Contagens in loco } \\
\text { Questionário }\end{array}$ \\
\hline CET (1983) & $\begin{array}{l}\text { Ensino Superior, } \\
\text { Cursinhos, } \\
\text { Escolas } 1^{\circ} / 2^{\circ} \text { graus } \\
\end{array}$ & 05 & $\begin{array}{l}\text { Viagens atraídas na } \\
\text { hora de pico }\end{array}$ & $\begin{array}{c}\text { № de alunos, } \\
\text { Área total de salas de au- } \\
\text { la } \\
\end{array}$ & $\begin{array}{c}\text { Contagens in loco } \\
\text { Questionário } \\
\text { Entrevista } \\
\end{array}$ \\
\hline CET (2000) & $\begin{array}{l}\text { Pré-escolar, } \\
\text { Escolas } 1^{\circ} / 2^{\circ} \\
\text { graus }\end{array}$ & 20 & $\begin{array}{l}\text { Viagens atraídas na } \\
\text { entrada do turno } \\
\text { Viagens produzidas } \\
\text { na saída do turno }\end{array}$ & $\begin{array}{c}\text { Turno, } \\
\text { № de usuários } \\
\text { (por categoria), } \\
\text { Taxa média de } \\
\text { ocupação do veículo } \\
\end{array}$ & $\begin{array}{l}\text { Questionário } \\
\text { Entrevista }\end{array}$ \\
\hline $\begin{array}{l}\text { Pitsiava- } \\
\text { Latinopoulu } \\
\text { (2001) } \\
\end{array}$ & $\begin{array}{l}\text { Fundamental, } \\
\text { Médio, } \\
\text { Superior } \\
\end{array}$ & $\begin{array}{c}\text { NA } \\
\text { NA } \\
9 \\
\end{array}$ & $\begin{array}{l}\text { Distribuição Modal } \\
\text { Viagens geradas } \\
\text { por dia } \\
\end{array}$ & $\begin{array}{c}\text { № de alunos, } \\
\text { № de funcionários }\end{array}$ & $\begin{array}{l}\text { Questionário } \\
\text { Questionário }\end{array}$ \\
\hline $\begin{array}{l}\text { Tectran } \\
\text { (2003a, 2003b, } \\
\text { 2004) }\end{array}$ & Ensino Superior & NA & $\begin{array}{l}\text { Viagens geradas } \\
\text { por dia e no horário } \\
\text { de pico } \\
\text { Viagens geradas } \\
\text { por turno }\end{array}$ & $\begin{array}{l}\text { № de usuários, } \\
\text { № de alunos }\end{array}$ & $\begin{array}{l}\text { Contagens in loco } \\
\text { Levantamentos } \\
\text { junto aos usuários }\end{array}$ \\
\hline $\begin{array}{l}\text { Erwing et al. } \\
\text { (2004) }\end{array}$ & $\begin{array}{l}\text { Fundamental, } \\
\text { Médio }\end{array}$ & $\begin{array}{l}709 \text { via- } \\
\text { gens }\end{array}$ & Distribuição Modal & $\begin{array}{c}\text { Renda, } \\
\text { Motorização, } \\
\text { Tempos de viagem, A- } \\
\text { cessibilidade } \\
\end{array}$ & $\begin{array}{c}\text { Pesquisa domiciliar } \\
\text { O/D }\end{array}$ \\
\hline Souza (2007) & Ensino Superior & 06 & $\begin{array}{l}\text { Viagens atraídas na } \\
\text { entrada do turno } \\
\text { Viagens produzidas } \\
\text { na saída do turno } \\
\end{array}$ & № de alunos do turno & Questionário \\
\hline \multirow[t]{2}{*}{ Bertazzo (2008) } & $\begin{array}{l}\text { Escolas ensino } \\
\text { médio públicas }\end{array}$ & 05 & $\begin{array}{l}\text { Viagens atraídas na } \\
\text { entrada do turno } \\
\text { Viagens produzidas } \\
\text { na saída do turno }\end{array}$ & $\begin{array}{c}\text { Categoria da instituição, } \\
\text { Turno, } \\
\text { № de alunos do turno, } \\
\text { № de professores e } \\
\text { funcionários }\end{array}$ & Questionário \\
\hline & $\begin{array}{l}\text { Escolas ensino } \\
\text { médio privadas }\end{array}$ & 05 & & & \\
\hline $\begin{array}{l}\text { Herz et al. } \\
(2007,2009)\end{array}$ & Ensino Superior & 13 & $\begin{array}{l}\text { Viagens geradas } \\
\text { por dia }\end{array}$ & $\begin{array}{c}\mathrm{N}^{\mathrm{o}} \text { de alunos, } \\
\text { Distância ao centro da } \\
\text { cidade }\end{array}$ & $\begin{array}{c}\text { Contagens in loco } \\
\text { Questionário }\end{array}$ \\
\hline $\begin{array}{l}\text { NA - não se aplic } \\
\text { Escola } 1^{\circ} \text { grau: co }\end{array}$ & $\begin{array}{l}\text { rque os estudos foran } \\
\text { ponde, atualmente, à }\end{array}$ & a instituiçõ & $\begin{array}{l}\text { specíficas } \\
\text { Educação Fundamen }\end{array}$ & & \\
\hline
\end{tabular}


Tabela 2. Síntese dos modos de transporte considerados em cada estudo

\begin{tabular}{|c|c|c|c|}
\hline \multirow[b]{2}{*}{ Estudo } & \multirow[b]{2}{*}{$\begin{array}{l}\text { Propósito } \\
\text { do modelo }\end{array}$} & \multicolumn{2}{|c|}{ Modo de transporte considerado } \\
\hline & & $\begin{array}{c}\text { Estimativa de número de viagens } \\
\text { de pessoas }\end{array}$ & $\begin{array}{c}\text { Estimativa de número de } \\
\text { viagens veiculares }\end{array}$ \\
\hline ITE (2008) & $(1)$ & & Automóvel \\
\hline CET (1983) & (2) & & Automóvel \\
\hline CET (2000) & $(3)$ & Automóvel, Ônibus, A pé & Automóvel \\
\hline Pitsiava et al (2001) & $(1)$ & Automóvel, Ônibus, Bicicleta, A pé & Automóvel \\
\hline TECTRAN (2003a) & $(1)$ & Automóvel, Ônibus, A pé & Automóvel, Ônibus \\
\hline TECTRAN (2003b) & $(2)$ & Automóvel, Van, Ônibus, A pé & Automóvel, Van, Ônibus \\
\hline TECTRAN (2004) & $(2)$ & Automóvel, Ônibus, A pé & Automóvel, Ônibus \\
\hline Erwing (2004) & (1) & $\begin{array}{l}\text { Automóvel, Ônibus escolar, Bicicleta, A } \\
\text { pé }\end{array}$ & Automóvel \\
\hline Souza (2007) & (3) & Ônibus, A pé & Automóvel \\
\hline Bertazzo (2008) & (3) & Ônibus, A pé & Automóvel \\
\hline $\begin{array}{l}\text { Herz et al. (2007, } \\
\text { 2009) }\end{array}$ & (1) & Automóvel, Ônibus, Bicicleta, A pé & Automóvel \\
\hline $\begin{array}{l}\text { Legenda: (1) Estimati } \\
\text { (2) Estimati } \\
\text { (3) Estimati }\end{array}$ & iagens atraíc & $\begin{array}{l}\text { produzidas e atraídas). } \\
\text { aa entrada do turno. } \\
\text { la entrada e viagens produzidas no saída do tur }\end{array}$ & \\
\hline
\end{tabular}

de PGV são cativas e tem freqüência elevada. A idade dos alunos nos diferentes níveis de ensino é fator preponderante nas possibilidades de escolha modal à disposição dos estudantes. Por exemplo, enquanto na pré-escola e nos primeiros anos do ensino fundamental os alunos são em geral transportados por seus pais ou usam transporte escolar, em séries mais avançadas do ensino fundamental e no ensino médio já existem outras opções, tais como caminhar, ir de bicicleta ou usar o transporte público.

Poucos estudos buscam compreender as variáveis explicativas da distribuição modal, e existe a tendência em admitir que as taxas e modelos de geração de viagens obtidos com base em uma amostra de instituições são diretamente aplicáveis a novos PGVs. Enquanto esse pressuposto é adequado para a estimativa das viagens totais de pessoas, no caso da estimativa das viagens veiculares a situação é diferente já que estas dependem da distribuição modal das viagens de pessoas. O padrão de viagens do novo PGV pode ser planejado para ser diferente do observado nas instituições da amostra, desde que os modelos de geração permitam compreender os fatores que afetam este padrão e tornem possível o estudo de cenários frente à aplicação de medidas de gerenciamento da demanda.

\section{NOVA ABORDAGEM}

As análises realizadas nas sessões anteriores mostram que o estudo de impacto dos polos geradores de viagem em geral, e das instituições de ensino em particular, podem servir como instrumentos de implementação de políticas públicas voltadas ao gerenciamento da mobilidade. Mantendo o conceito central da metodologia de Bryans and Nielsen (1999) é apresentada aqui uma nova abordagem para o estudo das viagens geradas em instituições de ensino.

Esta abordagem propõe a determinação de taxas e modelos de geração de viagens com base em análises da situação atual das instituições de ensino na área considerada, que possibilitem ao planejador: (i) definir exigências de projeto para o novo empreendimento para o atendimento das necessidades dos usuários, tanto dos que se deslocam por modos motorizados quanto por modos não motorizados; (ii) estudar o impacto dos novos empreendimentos sob diferentes cenários de padrão de viagens. Dada as características específicas deste tipo de empreendimento, as alterações previstas no padrão de viagens dizem respeito especificamente à distribuição modal e à taxa de ocupação dos automóveis. Na construção desses cenários, o planejador deverá levar em conta a possibilidade de implantar medidas que viabilizem expectativas realistas de mudanças no padrão de viagens nas instituições presentes em uma cidade. Isto é, as possíveis medidas de gerenciamento da mobilidade para uma dada região podem ser consideradas.

Para que os objetivos da nova abordagem possam ser alcançados são propostas: (i) novas categorias de viagens para as instituições de ensino; (ii) ajuste do procedimento atual para a determinação das taxas e modelos de geração de viagens; e (iii) novo procedimento para a realização dos estudos de impacto das instituições de ensino.

\subsection{Classificação das viagens geradas em instituições de ensino}

A abordagem proposta requer a definição de categorias de viagens que facilitem a compreensão das características das viagens geradas nas instituições de ensino e que, ao mesmo tempo, permitam a identificação das necessidades dos usuários da instituição de ensino em termos de elementos de projeto da edificação e de medidas de gerenciamento do tráfego nas suas imediações. Para tanto, considera-se importante classificar as viagens geradas pelas instituições de ensino nas se- 
guintes categorias:

a) viagens específicas: são as viagens realizadas com o propósito específico de chegar ou sair da instituição. Assim, as viagens não motorizadas e/ou de transporte público realizadas pelos alunos, professores e funcionários (consideradas em termos de viagens de pessoas) são classificadas como viagens específicas. As viagens específicas realizadas com o uso do automóvel, moto e veículo de transporte escolar, podem ser subdivididas em:

a.1) viagens específicas com estacionamento: realizadas por condutor que freqüenta a instituição, pressupondo um tempo de permanência do veículo no local. O veículo, portanto, chegará à instituição em um determinado horário, caracterizando somente uma viagem veicular atraída, e deixará o local em outro horário, definindo uma viagem veicular produzida;

a.2) viagens específicas sem estacionamento: realizadas com o fim específico de levar ou buscar usuários das instituições, por condutor que não freqüenta a instituição. $\mathrm{O}$ veículo chega e parte da instituição no horário de início e/ou término das aulas, caracterizando no mesmo período duas viagens: uma viagem veicular atraída e outra produzida. Este é o caso, por exemplo, dos pais que saem de casa especificamente para levar e pegar as crianças nas escolas.

b) viagens desviadas: viagens realizadas por veículos que alteram sua trajetória inicial devido à presença da instituição de ensino. Um exemplo é o caso dos pais que alteram o trajeto do seu deslocamento entre casa e trabalho, e vice-versa, para levar e pagar as crianças nas escolas. Em termos de impacto, esta categoria de viagens é similar às viagens específicas sem estacionamento.

c) viagens não-desviadas: viagens realizadas por veículos que já existiam antes da instalação do PGV, cuja realização não causa, em princípio, impacto na circulação geral do tráfego das vias adjacentes ao empreendimento. Usualmente elas não são consideradas para efeito da determinação das taxas e modelos de geração de viagens. No entanto, para efeito da nova abordagem proposta, o seu número precisa ser identificado e estimado para efeito do dimensionamento das áreas destinadas ao embarque/desembarque de passageiros junto às instituições. Se as paradas feitas pelos veículos junto ao PGV não ocorrem em local adequado, elas tam- bém causarão impacto na circulação do tráfego nas imediações do empreendimento.

\subsection{Procedimento para a determinação das taxas e modelos de geração de viagens}

As etapas previstas são a seguir apresentadas, seguindo a mesma sequencia da metodologia do ITE no que diz respeito à determinação das taxas e modelos de geração viagens. São elas:

a) definição do número de instituições a serem incluídas na amostra: recomenda-se estudar no mínimo 5 instituições de ensino, sendo preferível trabalhar com amostras superiores a 10 instituições. No caso de instituições que ofereçam ensino em diferentes turnos, com diferentes populações atendidas, os estudos devem ser desagregados por turno (cada turno é tratado como uma "instituição" específica);

b) seleção das instituições a serem analisadas para efeito da determinação das taxas e modelos de geração de viagens: usar os mesmos critérios da metodologia do ITE quanto à necessidade das instituições escolhidas representarem devidamente a população alvo;

c) definição das variáveis a serem estudadas em cada instituição da amostra: devem ser escolhidos dois conjuntos de variáveis. O primeiro diz respeito às variáveis com potencial de explicar a priori a realização das viagens pessoais de e para a instituição (independente do modo de transporte utilizado). O segundo grupo é composto por variáveis que tenham o potencial de explicar a escolha modal na realização das viagens (a renda dos usuários ou a propriedade de automóvel, por exemplo) e, ainda, a taxa de ocupação dos veículos;

d) coleta dos dados e período da pesquisa: a coleta dos dados deve ser feita, inicialmente, por meio de dois tipos de questionários. O primeiro, a ser respondido pela direção da escola, deve permitir a completa caracterização da instituição (características e dimensões das suas instalações físicas, períodos de funcionamento, número de usuários regulares, etc.). Os resultados deste questionário permitirão o planejamento da etapa seguinte da coleta de dados, que consiste na aplicação de um questionário aos usuários regulares de cada instituição (alunos, professores e funcionários). Este último questionário deve permitir identificar, no mínimo: quantidade de viagens geradas por dia da semana, em separado para cada categoria de viagem, permitindo a identificação do dia crítico em termos de geração de viagens; horários de maior concentração das viagens geradas (associados em geral 
ao início/término dos turnos de funcionamento da instituição); modos de transporte utilizados; taxas de utilização dos automóveis para cada categoria de viagem realizada por este modo de transporte; e a disposição dos usuários em mudar seu modo de transporte caso a oferta atenda suas necessidades, identificando qual o modo de transporte preferido e por que. Levantamentos complementares podem ser ainda necessários de modo a obter os valores para todas as variáveis identificadas na etapa anterior.

e) tratamento dos dados: os dados dos questionários aplicados aos usuários de cada instituição devem ser tratados de modo a produzir os seguintes resultados:

e.1) número total de pessoas chegam na (viagens atraídas) e partem da instituição (viagens produzidas) por turno, para o dia e horário de pico, desagregadas por categoria global de viagem (específica, desviada e não-desviada);

e.2) percentagem de viagens realizadas pelos diferentes modos de transporte, para as viagens específicas atraídas e produzidas (as viagens desviadas e não-desviadas, conceitualmente, são realizadas por modo motorizado do tipo automóvel, moto e veículo de transporte escolar);

e.3) número de usuários da instituição por veículo (taxa de ocupação do veículo), para cada categoria das viagens atraídas e produzidas realizadas por automóvel, moto e veículo de transporte escolar.

Os dados coletados para as variáveis explicativas selecionadas na etapa "c" devem ser também devidamente tratados.

f) definição de taxas e modelos: inicialmente devem ser realizados os estudos de correlação estatísticas entre as variáveis explicativas previstas (referidas no item "c") para a geração das viagens referidas no item "e.1" e o número de viagens geradas. Na sequencia, o mesmo tipo de análise deve ser feito para verificar a correlação entre as variáveis previstas para explicar a distribuição modal com os dados obtidos em “e.2” e, por último, a correlação entre as variáveis explicativas e os dados referidos em "e.3”. Esses estudos de correlação permitem a identificação das variáveis a serem utilizadas na elaboração das taxas e modelos correspondentes aos resultados observados na amostra para as situações referidas em "e".

\subsection{Procedimento para a realização de estudos de impacto}

O procedimento para a realização do estudo de impacto de uma nova instituição pressupõe, inicialmente, que sejam aplicados as taxas e modelos de atração e produção de viagens e se obtenha o número de pessoas que viajarão para e do estabelecimento de acordo com as categorias globais de viagens (específicas, desviadas e não desviadas). Este número servirá de base para o estudo de cenários a seguir apresentado. Na Figura 2 é apresentado o fluxograma das atividades previstas no procedimento proposto.

Como primeiro cenário, deve ser admitido que os usuários da nova instituição adotarão padrões de escolha modal e de utilização do automóvel similares aos observados nas instituições da amostra (Cenário 1). Isto significa aplicar sobre o número total estimado de viagens de pessoas todos os demais modelos obtidos, de acordo com os passos a seguir indicados:

Passo 1: usando as taxas e modelos correspondentes, estimar o número de viagens específicas (de pessoas) atraídas e produzidas realizadas pelos diferentes modos;

Passo 2: usando as taxas e modelos correspondentes, estimar o número de viagens veiculares (não considerar as viagens a pé e as realizadas por bicicletas e veículos de transporte coletivo) relacionado às seguintes categorias de viagens (em separado para as viagens atraídas e produzidas):

- viagens veiculares específicas com estacionamento;

- viagens veiculares específicas sem estacionamento;

- viagens veiculares desviadas;

- viagens veiculares não-desviadas;

Passo 3: usar o número estimado de viagens específicas realizadas pelos diferentes modos (exceto os considerados no Passo 2) para identificar, dentre outros aspectos: a necessidade de oferta de locais para estacionamento de bicicletas e de adoção de medidas para dar maior segurança à circulação desses veículos nas vias próximas ao empreendimento; quantidade, localização e tipos de dispositivos para a travessia de pedestres que devem ser ofertados para o atendimento dos usuários da instituição; localização de paradas de transporte público para facilitar o uso deste modo de transporte pelos usuários da instituição;

Passo 4: usar o número estimado de viagens veiculares específicas com estacionamento para dimensionar o número de vagas de estacionamento a serem oferecidas na instituição;

Passo 5: usar o número estimado de viagens veiculares específicas sem estacionamento, acrescido do número de viagens veiculares desviadas e não-desviadas, para dimensionar as áreas de embarque/desembarque 


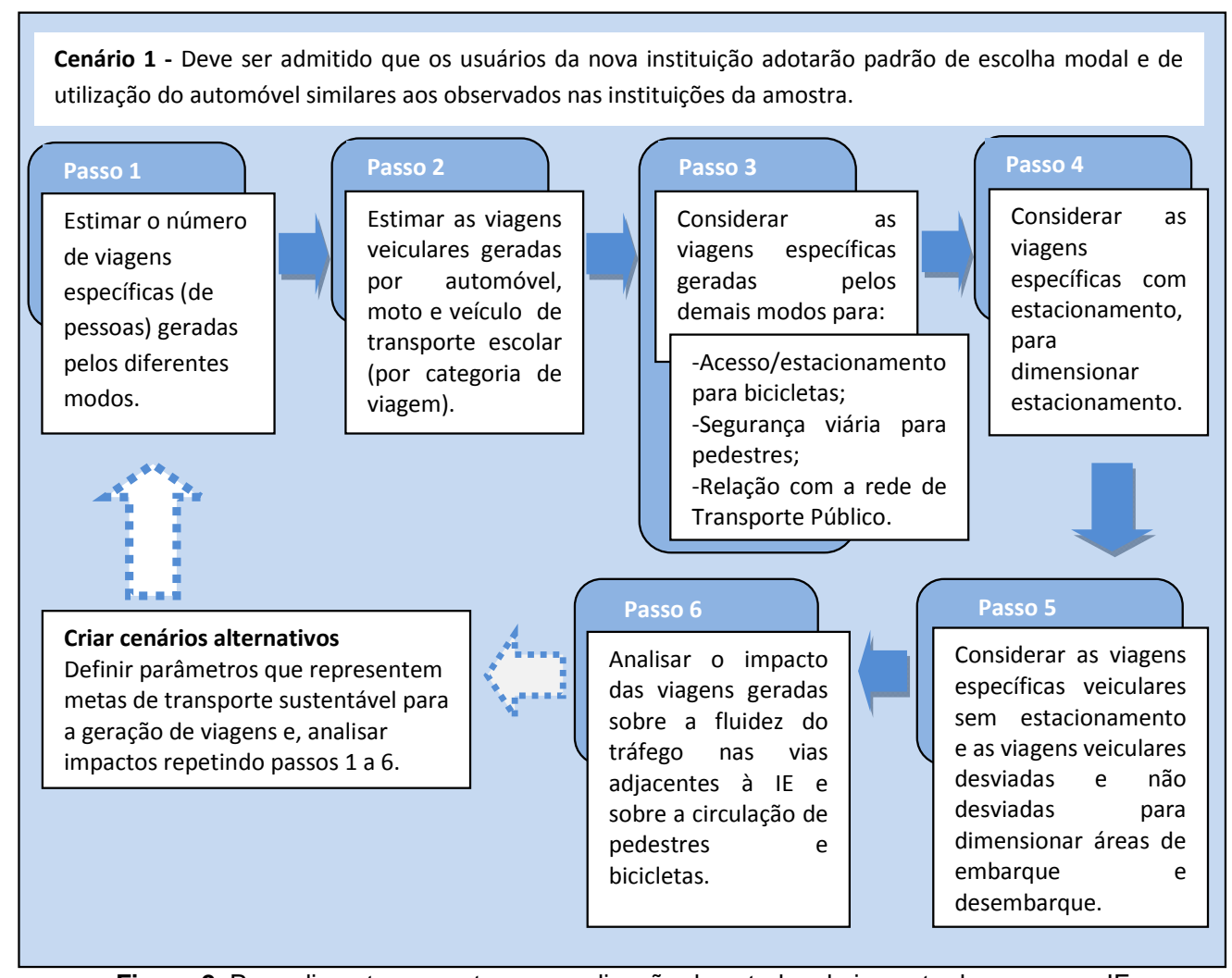

Figura 2. Procedimento proposto para realização de estudos de impacto de uma nova IE

de usuários junto ao(s) local(is) de acesso ao empreendimento;

Passo 6: analisar o impacto das novas viagens veiculares (específicas e desviadas) sobre a fluidez do tráfego nas vias próximas ao novo estabelecimento por meio de técnicas de simulação da operação do tráfego. Dependendo do simulador disponível, também é possível simular em conjunto as viagens específicas realizadas a pé e de bicicleta.

Na sequencia, criar cenários alternativos. Isto é, identificar intervenções que podem ser feitas no sentido de alterar a distribuição modal e a taxa de ocupação dos veículos de modo a atingir metas de transporte sustentáveis. A execução dos Passos 1 a 6, usando parâmetros representativos de um dado cenário, permite analisar o impacto da alternativa e compará-lo ao obtido para o Cenário 1 e para as demais cenários estudados.

\section{CONCLUSÕES E RECOMENDAÇÕES}

O estudo de impacto para a implantação de novos PGVs pode ser uma oportunidade para um gerenciamento mais sustentável da mobilidade nas áreas urbanas. Para que possa gerar dados úteis para este propósito, vários aspectos da metodologia comumente adotada nos estudos de geração de viagens para instituições de ensino merecem ser revistos e podem ser aperfeiçoados.

Neste contexto, o presente trabalho considera que os novos estudos voltados à definição de taxas e mo- delos de geração de viagens busquem compreender as variáveis explicativas da distribuição modal e do número de usuários por automóvel. Desta forma, será possível planejar o padrão de viagens dos novos PGVs e contemplar a aplicação de políticas de transporte mais sustentáveis orientadas na redução das viagens por automóvel. Para tanto, é apresentado um procedimento geral para a realização de estudos de impacto de uma nova instituição de ensino que faz uso da nova abordagem. Este procedimento permite que no estudo de impacto possam ser analisados cenários alternativos que levem em conta diferentes estratégias para alterar a matriz modal identificada nas instituições existentes, visando estimular o uso de modos de transporte mais sustentáveis.

A utilização do procedimento proposto apresenta as dificuldades inerentes aos estudos de geração de viagens por PGVs, especificamente no que tange à coleta e tratamento de um grande número de dados. Adicionalmente, o Passo 6 do procedimento impõe uma dificuldade adicional, na medida em que requer o uso de simuladores da operação do tráfego (motorizado e não motorizado) para a análise de cenários alternativos. Estes simuladores nem sempre estão disponíveis nas instituições responsáveis pela análise dos PGVs.

Finalmente, a inexistência de estudos que permitam a identificação de metas de geração de viagens sustentáveis para IES, que sejam viáveis para a situação específica de cada empreendimento, é a principal limitação da metodologia. Isto é, recomenda-se a realização de futuros trabalhos voltados à definição de taxas de 
geração de viagens por modo que viabilizem a implementação de políticas públicas específicas de mobilidade sustentável, e que levem em conta: as condições prevalecentes dos serviços de transporte público e da infraestrutura viária disponível para as viagens pelos demais modos; e as possibilidades dos setores público e privado envolvidos em melhorar as condições atuais para permitir que os modos alternativos ao automóvel sejam mais intensivamente utilizados.

\section{REFERÊNCIAS BIBLIOGRÁFICAS}

Bertazzo, A. B. S. (2008). Estimativa e Avaliação do Padrão de Viagens Geradas para Instituições de Ensino Médio. Dissertação de Mestrado. Universidade de Brasília, DF, 198p.

Bryans, W. and Nielsen S. (1999). An investigation into methodologies for determining a 'sustainable' trip generation rate. Traffic Engineering + Control, January 1999, pp. 13-16.

CET. Companhia de Engenharia de Tráfego (1983) Polos Geradores de Tráfego. Boletim Técnico 32, São Paulo.

CET. Companhia de Engenharia de Tráfego (2000) Polos Geradores de Tráfego II. Boletim Técnico 36, São Paulo.

Ewing, R., W. Schroeer, and W. Greene, W. (2004). School Location and Student Travel: Analysis of Factors Affecting Mode Choice. In Transport Research Record: Journal of Transportation Research Board, No. 1895. TRB. National Research Council. Washington, DC: 2004.

Herz, M., Galarraga J., Pastor G. (2007) Centros Universitarios Como Polos Generadores de Viajes. XIV CLATPU Congreso Latinoamericano de Transporte Público y Urbano, Río de Janeiro.

Herz, M., Galarraga J., Pastor G. (2009) Características de Generación y Distribución Modal de Viajes en centros Educativos Universitarios. XV CLATPU Congreso Latinoamericano de Transporte Público y Urbano, Buenos Aires

ITE - Institute of Transportation Engineers (2001). Trip Generation Handbook - an ITE Recommended Practice. Washington, DC.

ITE - Institute of Transportation Engineers (2008) -TRIP GENERATION, 8th Edition, Washington,D.C

Pitsiava-Latinopoulou, M., G. Tsohosz and S. Basbase. Trip generation rates and land use - transport planning in urban environment. In: Urban Transport VII: Urban Transport and the Environment in the 21th Century, pp. 297-306.

Shoup, D.C. (2001). Truth in transportation planning. Paper presented at Transportation Research Board $80^{\text {th }}$ Annual Meeting. January 2001.

Souza, S. C. F. (2007). Modelos para Estimativa de Viagens Geradas por Instituições de Ensino Superior. Dissertação de Mestrado. Universidade de Brasília, DF, 181p.

TECTRAN - Técnicos em Transporte Ltda (2003a). Relatório de Impacto na Circulação da Escola de Engenharia e da Faculdade de Ciências Econômicas da Universidade Federal de Minas Gerais. Belo Horizonte.

TECTRAN - Técnicos em Transporte Ltda (2003b). Estudo de Circulação e Estacionamento - Unidade Arcos - PUC Minas. Belo Horizonte.

TECTRAN - Técnicos em Transporte Ltda (2004). Relatório de Impacto na Circulação da Faculdade Estácio de Sá de Belo HorizonteCampus Prado. Belo Horizonte. 